WellBeing International

WBI Studies Repository

2012

\title{
Rational Engagement, Emotional Response, and the Prospects for Moral Progress in Animal Use "Debates"
}

\author{
Nathan Nobis \\ Morehouse College
}

Follow this and additional works at: https://www.wellbeingintlstudiesrepository.org/acwp_awap

Part of the Animal Experimentation and Research Commons, Animal Studies Commons, and the Bioethics and Medical Ethics Commons

\section{Recommended Citation}

Nobis, N. (2012). Rational engagement, emotional response, and the prospects for moral progress in animal use "debates". In J. Garrett (Ed.), The ethics of animal research : exploring the controversy (pp. 237-266). Cambridge, MA: MIT Press.

This material is brought to you for free and open access by WellBeing International. It has been accepted for inclusion by an authorized administrator of the WBI Studies Repository. For more information, please contact wbisr-info@wellbeingintl.org.

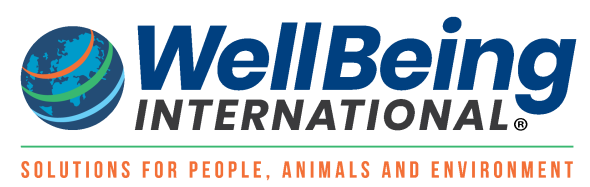


In Jeremy Garrett, ed., Animal Research in Theory and Practice (MIT Basic Bioethics Series, 2012), pp. 237-265, Chapter 14

http://www.animalresearchcontroversy.com/

14

\section{Rational Engagement, Emotional Response, and the Prospects for Moral Progress in Animal Use "Debates"}

Nathan Nobis

Morality is the effort to guide one's conduct by reason - that is, to do what there are the best reasons for doing. — James Rachels

\section{A Methodological Focus}

Synopsis: A focus of this chapter is on how to evaluate reasons for and against moral positions.

This chapter is designed to help people rationally engage moral issues regarding the treatment of animals, specifically in experimentation, research, product testing, and education.

Little "new" philosophy is offered here, strictly speaking. New arguments are unnecessary to help make progress in how people think about these issues. What is needed are improved abilities to engage the arguments already on the table, for example, stronger skills at identifying and evaluating the existing reasons given for and against conclusions on the morality of various uses of animals.

To help improve these abilities, this chapter sets forth a set of basic but powerful "logical skills" for rationally evaluating arguments. These skills emerge from reflection on some historical moral issues: an argument in defense of slavery, an argument against women being educated, and, as a nonhistorical case, an argument in favor of eating meat. These skills help us see these arguments' exact faults. And they are generally useful, for being applicable to any moral issue.

Dozens of common moral defenses of animal use are then evaluated using these skills. This application reveals that all of these arguments are unsound: they all have either false premises (and most animal experimenters agree, since they reject these premises) or premises that are in need of rational defense: questions about them need answers; and objections require responses or positive reasons must be given in their favor, or both.

This result is important. If animal experimenters and their supporters lack a sound argument that morally justifies animal use, then this fact must be faced with intellectual and moral integrity. Such integrity requires, at least, far more serious engagement with the issues, perhaps even some genuinely "new" philosophy. More likely, it requires widespread change in beliefs about, attitudes toward, and, especially, in the treatment of animals.

Demonstrating that no good moral reasons have been given in favor of much animal experimentation does not show that it is morally impermissible. In defense of this claim, it is observed that a broad, pluralistic case has already been made for the view that much, if not all, animal experimentation is wrong. This cumulative case is based on every major moral perspective that plausibly explains the moral relations among human beings, especially our obligations to vulnerable humans. The costs for rejecting this cumulative case are great, for both animals and human beings. 
Displaying this case is important, also, because many people seem to think that moral views highly critical of animal experimentation are "fringe" positions. They are not: they are supported by the most plausible moral principles and methods of moral reasoning that we know. Again, these facts need to be engaged more seriously.

It is possible that the preceding claims are mistaken and the arguments for them unsound. But what kinds of reasons are needed to try to show this, not just insist it? Methodological questions like this are the backdrop here. Explicitly discussing how to think about moral issuesin other words, how to identify, evaluate, and develop arguments - should improve what is thought about them. This focus should help prepare the way for more engaging and genuine debate on these issues and contribute to moral progress in thought, feeling, action, and policy.

\section{Why There Is a Moral Issue: Harms to Animals}

Synopsis: Animal usage is a moral issue because animals are harmed in experimentation.

Any time a being is harmed there is a moral issue: we can reasonably ask whether such harms are morally justified, whether there are good moral reasons for causing or allowing such harms.

How are animals harmed in experimentation? According to U.S. government estimates, each hour in the United States many people involved in education, the sciences, pharmaceutical and consumer products industries, and related fields and industries kill an average of at least 57,000 mice, rats, birds, dogs, cats, birds, primates, and other animals (USDA 2000). This adds up to 1.4 million animals killed per day, 500 million each year. (In contrast, around two million Americans die each year from all causes [US CDC 1997], and each hour over one million animals are killed to be eaten.) Exact figures are impossible to determine, in part, because rats and mice - over 90 percent of the animals used in experimentation - are not "animals" according to the Animal Welfare Act and so their numbers need not be reported.

Before they are killed, many of these animals experience at least some significant pain or suffering or both. When animal experiments are done to try to better understand diseases and injuries that afflict humans, semi-analogous conditions are induced in animals. So experimenters routinely drown, suffocate, starve, and burn animals; they blind animals and destroy their ability to hear; they damage animals' brains, sever their limbs, and crush their organs; they induce heart attacks, ulcers, tumors, paralysis, and seizures; they force them to inhale tobacco smoke, drink alcohol, and ingest various chemicals, poisons, and drugs, such as heroin and cocaine. ${ }^{1}$

In the unlikely event that animals have a pain-free existence in a lab, they are nearly always killed at the end of an experiment: if this were not true, then laboratories would feed and house animals for a natural lifetime, which they do not.

It is often assumed that if an animal is killed painlessly and without suffering, this is always morally permissible. This assumption is highly doubtful and, upon reflection, few people believe it anyway: if someone snuck up behind a healthy, young, and friendly but sleeping dog and painlessly killed her, this killing would not automatically be considered morally permissible even though it were done painlessly.

Many animals have interests at least in experiencing pleasure and well-being since these interests can be satisfied only if they are alive and conscious, they have derivative interests in being alive and conscious. Killing thwarts these interests; it deprives them of these goods. People who claim that painlessly killing animals is automatically morally permissible rarely try to explain why the reasons that death is typically a harm for human beings do not also apply to 
animals. Until they do, their assumption that a painless early death is always morally permissible or "humane" should be rejected.

The common assumption that even a pain-free life in a lab would not be harmful to animals should also be rejected. A recent scientific review shows that just being in labs and undergoing routine procedures (that are typically assumed to be benign) is harmful for animals. Eighty published studies were reviewed to show that "routine laboratory procedures commonly performed on animals: handling, blood collection, and orogastric gavage" (i.e., forced oral dosing of a substance) result in "rapid, pronounced, and statistically significant elevations in stress-related responses." The authors "interpret these findings to indicate that laboratory routines are associated with stress, and that animals do not readily habituate to them. The data suggest that significant fear, stress, and possibly distress are predictable consequences of routine laboratory procedures, and that these phenomena have substantial scientific and humane implications for the use of animals in laboratory research" (Balcombe, Barnard, and Sandusky 2004, 42).

Another scientific review about rodents, who are most used in experiments, reports, "Studies indicate that rats and mice value opportunities to take cover, build nests, explore, gain social contact, and exercise some control over their social milieu, and that the inability to satisfy these needs is physically and psychologically detrimental, leading to impaired brain development and behavioral anomalies (e.g., stereotypies)" (Balcombe 2006, 217). Since common lab housing arrangements do not meet these needs, they have these harmful results.

Thus, lab life and (early) death is bad for animals: it harms them, and harms them greatly. Everything is taken from them and with very few exceptions (e.g., therapeutic research where there is a sick or injured animal [whose condition was not induced by an experimenter], there is no existing effective treatment, and so the research is done for the expected betterment of that individual animal) they gain nothing. For these reasons, there is a moral issue that demands careful consideration. Animal experimenters should agree.

\section{Animal Experimenters and Emotional Reactions: Some Philosophers' Experiences}

Synopsis: Animal experimentation advocates often respond emotionally when confronted with reasons to think that animal experimentation is wrong.

Many experimenters insist that when they harm animals, such as in the ways mentioned earlier, they treat them "humanely," "with compassion" and with "due care and concern for their welfare."

Stuart Derbyshire, a scientist who defends animal experimentation, admirably insists that claims like these are "dishonest" because "no animal experiment is in the interests of animal welfare" (2006). He argues that "it is not possible to advocate animal welfare and at the same time give animals untested drugs or diseases, or slice them open to test a new surgical procedure" because "no animal experiments are in the interest of the animal" $(2006 ; 2002,39)$. He recognizes that "[o]nce the perspective of the animal is adopted, it is inevitable that all experimentation will be seen negatively" $(2002,39)$. He argues that animal experimenters should be truthful about the harms they inflict.

Experimenters generally do not respond well to Derbyshire's arguments. Instead, many seem to misunderstand them, and more seem to get angry. ${ }^{2}$ This is not surprising since they also often do not respond well to philosophers when they present reasons to support conclusions such as that some, much, or all animal experimentation is morally wrong, or even that animal usage is 
a serious moral issue. Indeed many respond emotionally, a characteristic typically, but often mistakenly, ascribed to animal advocates. Dale Jamieson reports his experience:

Scientists, like philosophers, are trained intellectuals who claim to value open debate and the disinterested search for truth. In light of all this common ground [between philosophers and scientists], it has often seemed peculiar to me that over the last fifteen years I have been involved with many acrimonious debates with scientists. What has seemed especially strange to me is that many scientists seem utterly unable to grasp abstract arguments, or go completely berserk on the subject of animal rights. When animal liberation is discussed, scientific rationality, detachment, and objectivity all too often go right out the window. (2002, 339)

Bernard Rollin, who perhaps has interacted with more scientists on these issues than any other philosopher has, describes similar experiences and remarks:

These anecdotes illustrate the total inability of defenders of research to mount proper ethical arguments given their unthinking adherence to their scientific ideology ["that 'science is value-free' in general and 'ethics-free' in particular]" $(2006,17)$. . . Ethics was, in their view, a matter of emotion, not reason, so one tried to win on emotion (112). . . . It is therefore not surprising that when scientists are drawn into social discussion of ethical issues they are every bit as emotional as their untutored opponents (20-21).

Mark Bernstein reports his experience of responses that although not emotional are otherwise disengaged:

For decades, activists have implored, cajoled, debated and sued those who oppress animals. Very little progress has been made, and in many ways the plight of the animals has worsened. . . . From my own experience, reflective of many on the "pro-animal" side, reason has had little effect. I have had literally a dozen debates on my campus with vivisectionists with no noticeable effect on animal testing this despite the fact that these experimenters are frequently "gracious" enough to concede that they cannot answer my objections to their use of animals. (2004, 102)

Perhaps these philosophers' experiences are not representative, but these reactions are not surprising. Rollin suggests, "there is perhaps no set of social issues on which otherwise sane people on either side of the question allow themselves to be overwhelmingly irrational as in matters pertaining to the treatment of animals, and our moral obligations to them" $(1992,12)$.

\section{Evaluating Arguments: "What Do You Mean?" and "Why Think That?"}

Synopsis: This section develops a basic theory of argument analysis that focuses on identifying clear and precise conclusions and premises, adding assumed but unstated premises when needed.

To help overcome emotional and disengaged responses to moral questions about animal use, it can be useful to consider some arguments about historical moral issues. Such issues can be useful for developing (or reminding ourselves of) some general skills in moral reasoning. Typically, we are emotionally, religiously, and financially distanced from them and common beliefs, feelings, attitudes, and behavior are generally better than they used to be: some moral progress has occurred. Many of our predecessors saw these as "controversial issues" but, 
fortunately, we can now see the faults with these arguments; it is partially for this reason that these issues are no longer controversial.

Here are three common, extremely simplified arguments that have been much debated throughout history, and, in some parts of the world, still are:

About slavery: Slavery is morally right because slave owners benefit from slave labor.

About women: It's morally wrong to allow women to get a higher education because women are such emotional beings that reasoning and abstract thought are quite difficult for them.

About animals: Since animals are not rational, it's morally permissible to raise them to be eaten. We would think poorly of anyone who makes claims about slavery and women like these, but one "respectable" thing about advocates of such claims is that they are arguing for their views. They are not just asserting their conclusions: they are attempting to give reasons and, from an intellectual point of view, this is preferable to giving no reasons at all.

However, their arguments are unsound because at least one premise is false (and we have good reason to believe this) or the premises do not logically lead to the conclusions stated. Three core "logical skills" help us see exactly why this is so about these arguments, and they will help us see what we should think about arguments in defense of animal experimentation also. Skills like these may seem obvious to many academic philosophers (who teach them), but —as the discussion to follow shows - they are not obvious to everyone. This fact and their potential for contributing to moral progress justify presenting them here.

Two logical skills are readily seen with regard to the argument about women. The stated conclusion $(\mathrm{C})$ of the argument is this:

(C1) It's morally wrong to allow women to get a higher education.

We should notice that this conclusion is imprecise: the number of women mentioned is unclear and so we do not exactly know what the argument's advocate means when he says what he says. He is claiming either (C2) It's morally wrong to allow some women to get a higher education.

or

(C3) It's morally wrong to allow any (i.e., all) women to get a higher education.

If (C2) is what's being said, we might rightly ask which women since perhaps there are (for whatever reason) some women (and some men?) who should not be allowed an education and so (C2) is true. Historically, however, the advocate of this argument has conclusion (C3) in mind, that no women should be able to get an education.

Thus, a first logical skill for identifying and evaluating moral arguments is the following: Make premises and conclusions precise in quantity: is something said to be true (or false) of all things (or people, or animals, etc.), or just some of them (and if so, which ones?)?

The stated reason, or premise $(\mathrm{P})$, in favor of this made-precise conclusion $(\mathrm{C} 3)$ is that (P1) Women are such emotional beings that reasoning and abstract thought are quite difficult for them.

This claim again is imprecise, between an "all" and "some" understanding of the claim. If the claim is this:

(P2) All women are such emotional beings that reasoning and abstract thought are quite difficult for them.

Then this can be shown false by finding at least one ("unemotional") woman who is capable of reasoning and thinking abstractly. The premise then must be this:

(P3) Some women are such emotional beings that reasoning and abstract thought are quite difficult for them. 
We could grant that (P3) is true: some women are like this (as are some men!). But how would this truth give any rational support for the argument's intended conclusion (C3), that it's morally wrong to allow any (i.e., all) women to get a higher education? How would some women's "emotionality" justify restricting educational opportunities for all women? And even if all women are so "emotional" and have such difficulty with "abstract thought," why would that justify denying any women the opportunity to better themselves through education?

There must be some unstated premise linking the made-precise premise (P3) to the madeprecise conclusion (C3) that answers these questions. Premises that offer these logical connections need to be general, universal claims so we can see the basis for the assumption that the stated premise(s) leads to and supports the conclusion. This leads us to a second logical skill: State (any) assumed premises so that the complete pattern of reasoning in an argument is displayed and it is clear how the stated premise(s) logically leads to the conclusion. Here this premise seems to be something like this:

(P4) If doing some activity is quite difficult for some people, then nobody should have a chance to do that activity.

(P4) and (P3) logically lead to (C3). But there is no good reason to think that (P4) is true. Sojourner Truth's response to objections to women's and African-American's rights is relevant here: "They talk about this thing in the head; what's this they call it? [Member of audience whispers, "intellect."] That's it, honey. What's that got to do with women's rights or Negroes' rights? If my cup won't hold but a pint, and yours holds a quart, wouldn't you be mean not to let me have my little half measure full?" (1851). Thus, to summarize this argument's faults: first, we do not know what exactly is being said when this argument is given because the stated premise and conclusion are imprecise. Once we make these claims precise, however, we see that one way of making the premise precise (the "all women" version) results in a false premise, which is enough for the argument to be unsound. The other way of making the premise precise (the "some women" version) is true but we can reasonably suspect that the unstated premise linking this to the conclusion is false, making the argument unsound again.

The slavery example further illustrates the need for revealing assumed, unstated premises linking premises to conclusions. The made-precise conclusion, uttered by the slave owner, that "slavery is morally right" follows from the (true) premise "slave owners benefit from slave labor" only when an assumed, unstated general premise is added, something like:

(P5) If one group benefits from the labor of another group, then it is right for the benefiting group to get those benefits.

This premise asserts that the mere fact that some group gets some benefits automatically makes that practice or action right.

But this premise is not true: successful bank robbers "benefit" from robbing banks; child molesters and rapists might "benefit" from their actions too (they apparently enjoy doing this, which is a benefit to them). But these actions are not right and so the benefits people get do not automatically make them right. So this argument is not sound, as it too has a false premise, namely (P5).

The nonhistorical argument in favor of eating animals illustrates a third logical skill. The stated conclusion is that

(C4) It's morally permissible to raise animals to be eaten.

And the stated premise is that

(P6) Animals are not rational. 
Both the premise and the conclusion are imprecise: is the person saying that all animals are not "rational," or just some of them (if so, which ones?)? That it's morally permissible to eat any animals or just some of them (again, if so, which ones?)?

This person probably means to be saying that all animals are not rational and that it is morally permissible to eat all animals. But there clearly is an assumed, unstated general premise linking the premise to the conclusion, something like:

(P7) If a being is not "rational," then it is morally permissible to raise and to eat him or her.

To evaluate this premise (as well as [P6] and other premises that might come from clarifying it), we need to use a third logical skill:

Clarify the intended meaning of unclear or ambiguous words.

The meaning of "rational" is not at all clear: we need to ask an advocate of this argument what he or she means by "rational." Suppose he responds, as some biologists have in trying to defend harmful animal use, with the observation that animals do not publish academic articles (McInerney, Morrison, and Schrock 2004). Suppose he claims that a being is "rational" only if it does that. This suggests this premise:

(P8) If a being is not "rational," i.e., she does not publish academic articles, then it is not morally wrong to raise her to be eaten.

If this premise were true, then it would be morally permissible to raise human babies to eat them since they do not publish articles. So, this premise has morally unacceptable implications, and animal experimentation advocates agree. Many other understandings of what it is to be "rational" would yield similar implications for human beings who are not "rational," for example, the severely mentally challenged, very old humans, and many others. Thus, this argument is unsound.

Through these case studies, three fundamental logical skills for identifying and evaluating arguments have been articulated. They amount to reaching clarity on what exactly people mean when they say things about moral issues and finding out why they think that, in other words, learning what their reasons are, including any unstated assumptions essential to their reasoning. "What do you mean?" and "Why think that?" are some of the most useful questions to ask, and patiently and carefully answer, in critical discussions of moral issues.

These three logical skills are just the application of basic logic to ethics. The preceding cases confirm their value. The skills are generally useful for identifying and evaluating reasoning. Discussions of ethics and animals issues would greatly improve if these skills were widely practiced.

\section{What the Issue Is Not: The Irrelevance of Rights, Equality, Importance, and Moral Status}

Synopsis: The fundamental moral question is whether uses of animals are morally permissible, not whether animals have "rights," are "equal" to, or are "as important" as humans, or any other comparative evaluation.

The fundamental moral question is whether or not any or all such experiments that involve seriously harming animals (i.e., nontherapeutic research) are morally permissible, meaning, not morally wrong, and what reasons can be given for one's answer.

There are a number of other issues that many people think are the fundamental question, but they are not. These distractions need to be addressed, using the logical skills developed earlier, before more direct arguments in defense of animal use are evaluated. 
The most common distraction involves unclear and imprecise appeals to "rights." Many people argue that "animals do not have 'rights' and so, therefore, the harms to animals from animal experimentation are not wrongly inflicted."

But the term "rights" is ambiguous and unclear so we must ask what someone means when he or she says animals have no rights. There are legal rights and, perhaps, there are moral rights. Animals have very few legal rights of any kind: there are very few, if any, things that someone could do to an animal, especially in an experimental setting, that would lead to criminal charges or penalties.

But the question of legal rights is not the issue. It is possible that an action is legal but morally wrong, and morally permissible actions can be illegal. Examples readily illustrate this legal-moral distinction: the fact that (early) abortions are legal in the United States does not necessarily mean they are morally permissible; whites' having a legal right to own slaves did not mean that slavery was morally permissible. In general, moral questions are not answered merely by consulting what legal rights anyone has or lacks. So, the law's permitting or even requiring animal experimentation does not show that it is morally permissible.

Perhaps then, the real issue about rights is whether animals have moral rights since there can be moral rights that are not protected by legal rights. This suggests a new argument: that "since animals do not have moral rights, animal experimentation is not wrong."

But what does the phrase "moral rights" mean? This question can be extremely confusing because of a variety of possible moral rights (e.g., moral rights to life, to not be caused harm, to not be "used" for the benefit of others, to be treated respectfully, to make one's own decisions and direct one's own life, to not be someone's "property," to not be caused "needless" pain and suffering, to have one's interests taken into consideration, to have a promise kept, etc.). There are many possible general and particular moral rights we might consider.

When some people hear the phrase "animal rights," perhaps particular moral rights come to mind, such as the (alleged) moral right to have a promise kept or a debt repaid. They then think that since animals do not make promises or take out loans, they do not have these moral rights and so some people conclude that animals do not have any moral rights. David Martosko, a spokesperson for a public relations firm representing animal use industries, reasons accordingly: "If you want to give rights to animals, then they should [be] expect[ed] to embrace responsibility in return. As soon as chickens can make a sensible decision at the ballot box and pay taxes, then they can have rights. Until then, chicken is for dinner" (Feldhahn and Glass 2006). Similarly, primatologist Frans de Waal claims, "The concept of rights applies only to those capable of carrying responsibilities within our society."3

Perhaps there are some moral rights an individual has only if she votes, pays taxes, and is generally responsible. But surely not all moral rights are like that: for example, if there are any moral rights, babies and young children surely have the moral right to not be tortured merely for the torturer's pleasure, yet they do not vote or pay taxes nor are they responsible members of society. Many other examples would show that arguments like these are very poor.

But suppose animals have no moral rights of any kind. Does that imply that harmful uses of them are morally permissible? No, it does not. As Tibor Machan, a philosopher who defends animal experimentation observes, moral "rights do not exhaust the field of morality" $(2004,21)$. And Carl Cohen, another advocate of animal use, observes, "Denying the reality of animal rights does not entail the denial of our obligations to animals" (Cohen and Regan 2001, 27).

It might sound odd to say, "Animals do not have any moral rights, but animal experimentation might still be morally wrong." But this could be true because harming animals 
might be wrong for reasons other than their having moral rights: for example, because doing so treats them disrespectfully, because harming them is cruel and not compassionate, because experiments treat animals in ways we wouldn't want to be treated and so violate the Golden Rule, because there are better things to be done than animal experimentation (i.e., other projects or research that would produce more goods, perhaps even just for humans), and so on.

To put these points formally, the conclusion of this argument does not logically follow from the premises:

If conscious, sentient animals have moral rights, then animal experimentation is morally impermissible.

But animals do not have any moral rights.

Therefore, animal experimentation is morally permissible.

As an instance of the logically invalid argument form "denying the antecedent," this argument provides no support for its conclusion because the premises do not even lead to the conclusion. Even if animals do not have moral rights that make harmful uses of them wrong, these uses could be wrong for other moral reasons.

Perhaps the intended argument then is this:

If conscious, sentient animals do not have any moral rights, then animal experimentation is morally permissible.

Animals do not have any moral rights.

Therefore, animal experimentation is morally permissible.

This argument's premises do lead to the conclusion, but it has the problem that the first premise is false, as Machan and Cohen point out. And, of course, what is meant by "moral rights" needs to be explained and reasons need to be given for thinking that no animals have any such moral rights. These reasons might not survive critical scrutiny.

To think about which moral rights, if any, an individual has, we must be very specific about which exact moral rights are under consideration: there are no "generic" rights for animals, just like there are no "generic" rights for humans. Once an exact, fully specified moral right identified, we can then consider the reasons for thinking that (any) animals (and humans) have such a right, and reasons to think that they do not. But one should not mistakenly think that if animals do not have some, or any, moral right(s) that it immediately follows that animal experimentation is morally permissible.

Similar observations about rights apply to claims that the fundamental moral question about animal use is whether animals are "equal" to humans, whether animals are as "important" as humans, whether animals' and humans' "moral status" is "equal," and other comparative claims.

All these notions are extremely obscure: what people mean when they say such things is not at all clear. It is not easy to give a plausible explanation of what it is to say that "all humans are equal," and explain why that is true (if it is) and thus why animals would be "not equal" to humans. Claims about moral status, standing, and importance are also obscure in meaning.

But even if no animals are "equal" to any humans, in the sense that no animal's interest should be given equal consideration to the comparable interest of any human (or none have the same "moral status," etc.), it doesn't follow that animals' interests should be given no consideration at all (or that they have no moral status, etc.). If that were true, then there would be nothing inherently wrong even with torturing animals for fun since their interests in avoiding pain and suffering need not be given any consideration whatsoever. 
For animal experimentation advocates who reject that implication, they must think that animals' interests need to be given some consideration, but less than is due to human interests. Some philosophers have argued that this kind of mid-level "amount" or "level" of moral consideration of interests, "importance," "standing," or "status" is enough to make some, much, or all animal experimentation wrong: their arguments deserve careful consideration. ${ }^{5}$

Since widespread confusion and miscommunication often result from discussing moral issues in terms of (moral) rights, equality, importance, moral status, and other comparative notions, it is better to not use these terms at all. This can be done with no losses: everything one would want to say can be more clearly said without these terms. What is better is just to ask directly whether some treatment of animals is morally permissible or not, and why.

\section{Why Many Arguments in Defense of Animal Experimentation Are Unsound: An Application of the Three "Logical Skills"}

Synopsis: Using the logical skills developed earlier in this chapter, this section shows how dozens of common arguments in defense of animal experimentation are unsound.

These logical skills will now be applied to other common arguments intended to show that animal use is morally permissible. In all cases, once we make the premises and conclusions clear and precise and, if needed, add the missing premise(s) needed to reveal the full pattern of reasoning, we see that each argument has at least one premise that is either false or in need of serious defense.

The discussion here is methodological, and this is intentional to show that there is a method for evaluating moral arguments. These same methods should be used in any critical responses to this chapter.

\section{"Benefits" Arguments}

Many people argue that there are medical benefits for humans that result from animal experimentation - such as treatments and cures for diseases, improvements in health, and so forth — and that, therefore, animal experimentation is morally permissible. The suggested argument is this:

(P1) Animal experimentation benefits humans.

(C) Therefore, animal experimentation is morally permissible.

There are many problems with this argument. First, (P1) is imprecise in many ways. Much animal experimentation is done without any expectation that it will yield (medical) benefits for humans. So (P1) should claim that some animal experimentation benefits humans. But there is more imprecision. It says either

(P2) Some animal experimentation benefits some humans.

or

(P3) Some animal experimentation benefits all humans.

(P3) is false. About thirty thousand people, many of whom are children, die each day from starvation, malnutrition, and lack of very basic medical care. Since these people's quality of life is so very poor, it is hard to see how their lives have been made better by animal experimentation: these people, and at least millions of other humans, do not benefit from it.

About (P2), as it is stated, few scientific, humanistic, or ethical critics of animal experimentation deny it. There have been many, many experiments on animals. To claim that not 
one of them has led to any benefits for any humans — even just by good luck—would be to claim something false.

So (P2) is true: some humans benefit medically from some animal experimentation. Some people seem to think this automatically shows that animal experimentation is morally permissible. Oddly, they often seem to think this supports a more precise conclusion that all animal experiments are permissible, even those that do not lead to any benefits for humans and are expected not to. But no such conclusions follow, for many reasons.

First, just because some humans benefit from something does not entail that it is morally permissible for them to get it. For example, some people might benefit from an extremely expensive medical procedure, or from receiving vital organs taken from living, healthy people. But those benefits do not automatically justify directing so much money toward them (at the expense of others) or killing innocent people to take those organs.

To assume something different about animal cases (i.e., that it is morally permissible to seriously harm animals to benefit humans) just assumes that animal experimentation is permissible: it does not give any reasons in favor of that. As we saw before, common claims about rights, importance, and moral status do not justify this assumption.

Some might respond with the (true) observation that animals are not human beings, or are not persons, thinking that this shows that harming animals is permissible. They might claim that vivisecting humans would be wrong, but harmful animal experiments are not.

While this again assumes what is at issue, we should ask why it would be wrong to vivisect humans. The answers "Because they are human beings!" or "Because they are persons!" is unhelpful because we sensibly ask what is it about human beings, especially vulnerable ones (who are not "rational" or autonomous and lack intellectually sophisticated minds) that would make vivisecting them wrong. The best answers here will ultimately appeal to facts about humans' capacity to experience pain, to suffer, and to be deprived and lose various goods.

In short, it is human beings' ability to be harmed that is fundamentally morally relevant, not that they are human beings or that they are persons. Since many animals can also be harmed in comparable ways, the observation that animals are not human beings or persons does not show that harmful animal experimentation is morally permissible.

The second reason the preceding argument fails is that even if many humans benefit from a practice, that does not automatically morally justify it since all the relevant costs and benefits must be accounted for. An advocate of a benefits argument likely thinks that harms to animals matter morally but that the benefits to humans are (far) greater than the harms to animals, and this contributes to the moral justification for animal use. It is not just that there are some benefits to some humans, as (P1) asserts, but that the quantity, quality, and "seriousness" of these benefits for many humans are immense, far greater than the harms to animals.

Claims like these are common, but to make such claims reasonably, one needs reasons. To have these reasons, one must have a method to quantify and compare all the relevant benefits and harms, among species and between species.

Of course, benefits to any humans must be determined. This would often be a challenge because these benefits, if they exist, would often be indirect and distant, usually unknown, often unlikely, and often merely possible. Harms to animals, which are direct, immediate, and known, must also be measured. Furthermore, rare benefits for any animals must be calculated.

But still more information is needed: direct harms to humans from animal experimentation, for example, any unsafe drugs and procedures deemed safe in part because of misleading results from animal experiments, must be measured. And losses of benefits to 
humans, for example, any drugs that would be good for humans but are lost due to misleading animal data, would need to be calculated also.

But that's not all: further indirect harms to humans from animal experimentation must be factored in. When time, money, and talent are invested in animal experimentation and not in programs and research that are known to produce great human benefits, it produces an "opportunity cost," a loss of benefits for humans. This loss must be calculated.

Animal experimentation advocates sometimes claim that nearly all medical benefits have come from animal experimentation. Some scientists, health professionals, and philosophers argue that the medical benefits of animal experimentation are often exaggerated.

But clearly not all medical benefits have resulted from animal experimentation. Improved sanitation, better nutrition, more exercise, lessening unhealthy habits (e.g., smoking); as well as broader access to better health care, clinical research, autopsies, epidemiology, public health education and programs, technology-based research methods, education, cleaner environments, and many other methods of research and health care distribution-all of these benefits that are not owing to animal experimentation have significantly improved human health, safety, and well-being. People tend to overlook this.

Would more of these other (medical and nonmedical) methods of benefit production be used if there were less, or no, animal experimentation? Would this result in more or fewer benefits, somehow overall or even just for humans? These questions must be answered, in order to calculate the overall harms and benefits from animal experimentation.

Medical history that suggests that social and environmental changes, as compared with medical intervention, have been most responsible for reduced death rates. Historians estimate that "perhaps 3.5 percent of the fall in the overall death rate can be explained through medical interventions for the major infectious diseases" (Singer 2002, 90-91). Peter Singer reports that since "this 3.5 percent is a figure for all medical intervention, [t]he contribution of animal experimentation itself can be, at most, only a fraction of this tiny contribution to the decline in mortality" (ibid.). People tend to overlook this also.

Therefore, the individual and total measurements and calculations needed to support a benefits argument would be very, very difficult to establish. The conceptual and empirical work needed to make such a calculation has never been done. Thus, claims that the benefits to some humans outweigh the harms to animals (and the harms to other humans!) are mere assertions: nobody has the evidence needed to justify them.

The third reason the benefits argument fails is the most important. Suppose someone developed a method to find and assess the evidence to support, for example, a claim that animal experimentation produces the greatest overall benefit. While some people think this would demonstrate that animal experimentation is morally permissible, it does not. To validly use reason to reach that conclusion, we need to add a missing premise, something like:

(P4) If many humans medically benefit from some action or practice, then that practice is morally permissible.

But (P4) is false and animal experimenters do not accept it: in general, benefits gained, even for many humans, do not automatically make an action morally permissible. Some, even many, humans benefiting at the serious expense of other humans does not immediately entail that some harmful practice is permissible.

Perhaps there are good reasons to think differently about animals, but this argument does not provide them. To insist that (P4) is false when we consider harming humans, but true when animals are harmed, is to assume that animal experimentation is morally permissible, not to give 
reasons in favor of thinking that. Until the arguments' advocates develop and defend these reasons, the benefits argument should be regarded as unsound.

A few other issues about this kind of argument should be discussed. Its advocates often present a historical timeline of medical benefits for humans they claim resulted from animal experimentation. These timelines might not show what their advocates claim, for while animals were often involved somewhere in the development of the treatment, they might not have been the cause of the medical benefit. Perhaps the benefit, or a greater benefit, would have been realized even without the animals. To determine this, a lot of historical research into the details of the cases would be required, far more than what is typically given.

The outcome of this historical research still would not show that this animal use was morally permissible, however. That conclusion would follow only if some historicized version of (P4) were true:

If some benefits came from some action, then doing that action is morally permissible (and it is, or would be, permissible to keep doing it).

Easy counterexamples, given earlier, refute this principle. But biologist T. R. Gregory has responded to these historical arguments with this claim: "Wind- and steam-powered vessels were certainly vital in the exploration of much of the globe, but this fact in no way indicates that they should continue to be seen as useful even as newer and more efficient technologies develop. In this regard, scientific arguments for and against the use of vivisection are best addressed in the context of modern medical research" $(2000,163)$.

Again, the fact that there were benefits does not show that the humans' benefits outweighed the animals' harms. It does not show that there were not other practices that would have yielded either the same or different greater benefits for humans; it does not show that there are not current non-animal-involving activities that would yield greater benefits for humans; and, finally, it does not immediately justify a practice whatever the benefits are.

The claim that some animals benefit from some (nontherapeutic) animal experimentation does not justify this experimentation either. The common claim that "the species benefits" is misleading also: some individual members of a species might benefit, but this does not immediately make an action morally permissible. We reject analogous arguments in defense of harmful, nonconsenting experimentation on humans: we would not accept "the species benefits" defense in these cases, and we need reasons why we should think differently about animals. Those who make these suggestions generally do not give these reasons.

Finally, about arguments from benefit, philosopher Ray Frey notes, "Whatever benefits animal experimentation is thought to hold in store for us, those very same benefits could be obtained through experimenting on humans instead of animals. Indeed, given that problems exist because scientists must extrapolate from animal models to humans, one might think there are good scientific reasons for preferring human subjects" $(2001,200)$.

Most animal experimentation advocates claim to reject what might be called "human vivisection": it would be wrong to force humans, especially vulnerable individuals, to undergo procedures routinely done to animals. Frey argues that the benefits arguments for animal experimentation might justify human vivisection, unless some relevant reason can be given to justify different consideration for the two kinds of (conscious, sentient) beings. Frey thinks there is no such reason. While no such reason was found in this section, perhaps it will be found in the one that follows. 


\section{"Necessity" Arguments}

Related to the benefits argument is the argument from "necessity" or the claim that animal experiments are "essential": in other words, animal experiments are necessary and therefore, are morally permissible. To evaluate this argument we must first ask what is meant by "necessary"?

There is a sense of the term according to which animal experimentation clearly is necessary: to do experiments on animals, it is necessary to do experiments on animals. This is true because to do any exact, particular action, it is necessary to do that action.

This is probably not what animal experimentation advocates mean by "necessary." They probably mean to say that it is "necessary" for medical benefits, that animal experimentation is "necessary" to most effectively retain and improve human health.

But which humans? If someone suggests that animal experiments are "necessary" to promote the health of all humans, this is surely false. Charles Fink argues: "The medical establishment is actually quite selective in its compassion for humanity since the vital interests of most people would be better served if animal research were abolished and our limited resources devoted to other forms of humanitarian aid, such as providing food and basic medical care to the poor. (1991). .5

Fink and many others argue that what's "necessary" to best promote human health are activities other than animal experimentation: this might include new non-animal-based research, but it would certainly include implementing and distributing existing, effective, and often inexpensive ways to improve livelihood, health, and well-being.

Perhaps animal experiments are "necessary" to promote the health of some humans: perhaps without some animal experiments - for whatever reasons - people will be seriously worse off. This, however, again does not immediately show that animal experimentation is morally permissible. Just because an individual needs something does not mean it is morally permissible for that person to get it: examples in the earlier discussion of the benefits argument show this. To insist we should think differently about animal cases again just assumes that animal experimentation is permissible: it does not give any reasons in favor of that.

Finally, an advocate of these arguments assumes a moral premise like the following: If doing some action is "necessary," then it is morally permissible.

To evaluate this premise (and any other claims about the necessity of animal experimentation), we must, of course, understand what its advocate means by "necessary." For some of the meanings that advocates of animal experimentation attach to that claim, it will be false to say that all—or even much—animal experimentation is "necessary." For these meanings, this moral principle has no implications.

There are other meanings of "necessary," however. For example, to say something is "necessary" could be to say "it couldn't be achieved in any other way." Given this meaning, many animal experiments are "necessary." But, following Frey's suggestion, given this meaning some human vivisection is also "necessary" since some benefits from it also "cannot be achieved in any other way." Therefore the previous principle implies such human vivisection is not wrong.

To insist that this "necessary" human vivisection would be wrong (which is what we should think, as animal advocates and many animal experimenters insist) is to claim that the previous principle is false. To then claim that the principle is true for animals - that "necessary" animal experimentation is not wrong - is, again, to assume the conclusion that requires moral defense. 
Perhaps reasons can be found to justify this assumption. As it stands, however, since an action's being "necessary" - in almost any sense of the term - does not automatically entail that the action is morally permissible, these arguments are unsound.

\section{"No Alternatives" Arguments}

It is also sometimes argued that there are "no alternatives" to animal experimentation and, therefore, it is morally permissible.

What does it mean to say this? As with necessity arguments, there is a sense in which there clearly are "no alternatives" to animal experimentation: to experiment on an individual or species of animals there is no alternative than to experiment on those animals (whether these results will reliably predict a different animal's or species' [especially humans'] responses is a separate issue, however). This claim is true because to do any particular action, one must do that exact action. In this sense, for each action, there are "no alternatives" to doing that action than to do that action.

But this probably is not what animal experimenters mean when they claim there are no alternatives. Perhaps what is being said is that there are no alternatives to animal experimentation that will produce medical benefits, or as many benefits for as many humans. But again, there are many ways to address human disease and improve health and these, unlike most animal experiments, are certain to improve human health. Some of these methods might produce the same benefits (if there are any) that could come from animal experiments; others might result in different, perhaps greater benefits. Either way, the claim that there are no alternatives is false. Furthermore, if animal experiments generally do not lead to human benefits, then we do not want an "alternative" to them: we just want research methods (and other activities) that are effective.

But the "no alternatives" argument also presumes this unstated, false moral premise: If there are "no alternatives" to doing an action, then doing that action is morally permissible. For many actions, there are no alternatives to doing them: to do that action or get that exact information, there is no alternative but to do that action. Yet some of these actions are morally wrong. Therefore, this unstated moral principle is false.

There is one basic, obvious "alternative" to animal experimentation, namely that it not be done. Advocates of animal experimentation need to give reasons why this is not a morally obligatory alternative, especially if a strong case can be made that much, if not all, animalharming experimentation is wrong.

\section{"There Must Be Some Level of Benefit ... ?"}

Before concluding this section, it's important to discuss the intuition that there must be some level or kind of benefits that would justify animal experimentation. This judgment is likely true, but - as the reasoning in this chapter supports - only if it is also likely true that there must be some kind of benefits that would justify human vivisection that entailed, for example, giving (vulnerable) humans cancers, heart disease, breaking their limbs, doing burn tests, and so on.

Many people would argue that this would be wrong, (almost) no matter the consequences. Cases can be developed, however, to justify a sense that doing this could be moral, but only in extreme, contrived cases (e.g., to avoid the destruction of the world). This abstract possibility, however, would not justify any actual human vivisection; in other words, no vivisector of human beings could justify himself by claiming, "There must be some benefits that could possibly justify what I am doing!!” 
The same is true about animals. We do not need a theory of what level of benefits (if any) could justify human vivisection to condemn it. To think differently about animals is to accept a double standard, one that likely cannot be justified by strong arguments.

\section{Other Arguments Evaluated Online}

Due to space constraints, regrettably only the arguments that are the focus of this volume can be discussed here. In an appendix available at NathanNobis.com, dozens more defenses of animal experimentation are evaluated, including arguments from

1. utilitarianisms;

2. Hobbesian egoistic contractarianisms;

3. an anti-Golden Rule ("do unto others what you would not want done to you");

4. evolution and "scientific" perspectives on morality;

5. the fact that experimenters find their work "interesting" or "fun" and it produces some knowledge;

6. animals' (alleged) lack of personhood;

7. animals' not being human beings;

8. moral partiality and who "we" care about the most;

9. "humanity's" admirable accomplishments;

10. religions and divine commands;

11. moral nihilisms and relativisms;

12. animal advocates' (alleged) hypocrisy and misplaced priorities;

13. name calling;

14. and many more.

Many arguments appeal to claims about humans' sophisticated mental capacities (e.g., moral concepts, responsibility, autonomy, intellectual achievement, etc.) and the premise that it is wrong to seriously harm an individual only if she has such capacities. But since not all humans have these abilities, these arguments support human vivisection.

To try to avoid refutations based on this demand for precision, complex premises like this are engineered:

If an individual is a member of a species or a "kind," or a group for which it is "normal" to have these sophisticated mental capacities, or the individual has the "potential" for them, then that individual has all the moral properties that arise from these capacities, despite not having these capacities him- or herself.

For all these dozens of arguments and responses to the issue, if clear and precise conclusions and premises are identified and, when needed, missing premises are added to make the reasoning explicit, we see that they are all unsound.

The recognition of the cumulative failure of defenses of animal experimentation justifies the judgment that there is no moral justification for harmful animal experimentation. To give reasons to think that this claim is false, one must produce arguments that do not fall prey to the methods of argument analysis developed in this chapter: it's that simple.

\section{A Cumulative Case for the Immorality of Most, If Not All, Harmful Animal Experimentation}

Synopsis: Thinkers from nearly every moral-theoretical perspective have defended reasons to think that most, if not all, animal experimentation is morally wrong. 
For many people, once they see that that the moral defenses of animal use are weak and how one demonstrates this, they are then more open to considering the positive moral cases in defense of animals.

Prior to this, their views are often held in a manner similar to how Fred Feldman describes many people's views on abortion: "divorced from reflection on morality in general," formed "without considering the more general moral principles from which these particular [views] would follow" $(1992,192)$.

Logical methods of thinking can force us to revise our moral judgments so they are based on principles and methods of moral reasoning that "have rational backing" and are "derived from something that has independent intuitive appeal" (Feldman 1992, 192). This forces us into moral theorizing, developing and evaluating hypotheses about what, in general, makes right acts right and wrong acts wrong.

Interestingly enough, ethicists from nearly every moral-theoretical perspective have argued that most, if not all, animal experimentation is morally wrong. David DeGrazia notes, "The leading book-length works in this field exhibit a near consensus that the status quo of animal usage is ethically indefensible and that at least significant reductions in animal research are justified" (1999, 25; emphasis in original). So, cases have been made from

1. theories that posit a moral right to respectful treatment owed to all conscious and sentient beings, not just those who are conscious, sentient, and biologically human (rights theories);

2. theories that demand we evaluate our actions from an imagined state of ignorance of our race, sex, mental abilities, and species so we protect the self-interest of whichever experiential self we could be (ideal contractarianisms);

3. Golden-Rule ethics that require us to ask how we would like it if we were treated the way we plan to treat others;

4. theories that acknowledge that all conscious, sentient beings - not just the "self-conscious" should be treated as "ends in themselves" and not be used as "mere means" (modified Kantianisms);

5. consequentialisms that demand we impartially produce the greatest overall good(s);

6. virtue ethics, which require us to act from compassion and sympathy;

7. moralities based in a common-sense principle that we should cause the least harm, especially to the innocent and vulnerable;

8. Christian, Jewish, and other religious moralities, basing their principles on Scripture, tradition, and theology; and

9. many more.

All these theories accept the basic principle that like cases should be treated equally unless there is a relevant reason to think otherwise. They thereby support the judgment that, insofar as vivisecting vulnerable humans is wrong, animal experimentation is also wrong, since no morally relevant differences between the cases can be found.

This cumulative plurality of theoretical riches given in defense of animals should be engaged more deeply. Many people's own moral principles, combined with what they think vulnerable humans morally deserve and, upon reflection, their best reasoning for why they think that, likely have profound implications for their views on animal use. 


\section{Recommendations}

Synopsis: This section offers some "logical-skill"-based recommendations for making moral progress, and acknowledges financial, social, and gustatory barriers to fair, impartial critical thinking about animal use.

In conclusion, the plight of animals exists for many complicated reasons: tradition, power, money, politics, law, ignorance (scientific and otherwise, including among scientists), a lack of imagination, a narrow understanding of how to make people better off, apathy, greed, selfishness, frivolity, and many other causes.

Generally underdeveloped abilities in moral reasoning and argument analysis surely also are a factor. In summarizing the arguments that were given in defense of African slavery and against women's and homosexuals' rights, Regan comments, "To recognize that some of the best scientists and scores of learned Christians may have offered defenses of evil may help make us more receptive to the possibility that the same thing could be happening today" $(2001,107)$.

Yet moral progress has occurred in these areas. This is, in part, due to what we think and how we reason. Some might insist it is impossible that their views about animals are mistaken and their favorite arguments unsound, but they would have a hard time explaining why: we make moral mistakes in other areas, so why not about animals also?

Logical methods of moral reasoning can make a difference. A first recommendation is that these skills be practiced on other moral issues and then rigorously applied to arguments about animal use, starting with those in this book

Some experimentation advocates might disagree with this recommendation, however. DeGrazia comments: "Biomedicine ... has created a political culture in which many or most animal researchers and their supporters do not engage in sustained, critical thinking about the moral status of animals and the basic justification (or lack thereof) for animal research. Few seem to recognize that there is significant merit to the opposing position, fewer have had any rigorous training in ethical reasoning, and hardly any have read much of the leading literature on animal ethics" (1999, 25). And Richard Vance (1992) observes that, due to a number of common "myths" and "oversimplifications" about philosophical defenses of animals, "Defenders of [animal] research often miss the mark in their analysis and criticisms" and "need to understand more adequately its basic philosophical foundations."

This disengaged and uninformed "culture" is not surprising. First, most people eat animals: if the defenses of animal experimentation are weak, then the defenses of harming animals for the pleasure, convenience, and custom of eating them are surely weaker. Many people want to avoid this implication, so avoid serious engagement with the issues.

Second, it is likely against many animal experimentation advocates' (perceived) selfinterest to be well informed about the moral arguments and to pursue them rigorously. The same is likely true about some bioethics instructors and students.

Philosopher Hilde Lindmann explains, "When you are rubbing shoulders with those who call the shots, you are apt to absorb the shot-callers' values and points of view, and that can make it difficult to retain your own sense of what matters. In fact, your job as a bioethicist can depend on your taking your client's point of view" $(2006,115)$. Thus, if the "shot-callers" support animal use, that influence can be difficult to resist.

She quotes bioethicist Carl Elliot (2001, 10-11) who points out:

It is a rare hospital [or college or medical or graduate school] that will keep on its

payroll a[n] ... ethicist who constantly and publicly criticizes ... policy. [And] it 
is a rare corporation that will continue to fund bioethicists who are constantly and publicly criticizing corporate policy ... [I]t is not good business to give money to the very people who are criticizing your marketing practices in the developing world, who are calling for a halt to your stem cell research, who are lobbying to place limits on the life of your drug patents, or who are attempting to block your clinical trials. The fact that this is not good business is exactly why bioethicists should be wary.

It is also rarely "good business" to criticize animal use.

A second recommendation then, at least for educational contexts, begins with Gregory Pence's (2000) classification of bioethicists into "inside" and "outside" varieties. The former work "inside" medicine and, Pence argues, are apt to "abhor controversy" and resist broad critique of the system and change, in part, because their financial and social support can depend on it.

For animal issues, these attitudes can contribute to an undefended assumption that animal use must be morally justified, a hazy sense that there just must be good arguments for it and the objections weak, and thus a lack of interest in pursing the issues rigorously. There typically are no professional benefits to taking animal ethics seriously in these contexts: indeed, doing so is often risky.

In contrast, Pence characterizes "outside" bioethicists as "big picture" thinkers who "are more likely to be comfortable allowing all sides of an issue to be heard" $(2000,192)$. They tend to come from academic contexts where pro-animal use attitudes are generally not (as) financially or socially required, or both.

Thus, a second recommendation is that outside bioethicists be prominently involved in discussions of these issues. Students can expect them to provide a more fair, impartial, and rigorous evaluation of the arguments, one that, as James Rachels (1996) puts it, "does what philosophers ought to do: challenge the prevailing orthodoxy, calling into question the assumptions that most people unthinkingly make."

A third recommendation, from Rollin, is that "all graduate education in science include a mandatory philosophical and ethical component of at least one year in duration, as well as historical depiction of past wrongs. Thinking in ethical terms must be made part of scientific thinking and this can only be achieved by education" (2006, 97-98) And a fourth recommendation, from DeGrazia, is that animal experimentation advocates and critics "take courses in ethical theory or animal ethics to promote knowledgeable, skilled, broad-minded discussion and reflection" $(1999,32)$.

Were these few recommendations followed, the quality of rational engagement with these issues would surely improve and moral progress would follow. Let the debate begin!

\section{Notes}

1. This list of procedures is from chapter 7 in this book, "Empty Cages: Animal Rights and Vivisection" by Tom Regan.

2. See replies at http://classic.the-scientist.com/news/display/23256/ (accessed July 11, 2011)

3. Cited in Douglas 2007.

4. See DeGrazia 1996, chapter 13 in this book, and Zamir 2007.

5. Singer $(2002,92)$ also writes in Animal Liberation: "Those who are genuinely concerned about improving health care would probably make a more effective contribution ... if they left 
the laboratories and saw to it that our existing stock of medical knowledge reached those who need it most."

\section{References}

$<$ jrn>Balcombe, J. 2006. Laboratory environments and rodents' behavioural needs: A review. Laboratory Animals 40: 217-235.</jrn>

$<$ jrn>Balcombe, J., N. Barnard, and C. Sandusky. 2004. Laboratory routines cause animal stress. Contemporary Topics in Laboratory Animal Science 43 (6): 42-51.</jrn>

$<$ edb>Bernstein, M. 2004. Legitimizing liberation. In Terrorists or Freedom Fighters? ed. S. Best and A. Nocella, 93-105. New York: Lantern Books.</edb>

<bok>Cohen, C., and T. Regan. 2001. The Animal Rights Debate. Lanham, MD: Rowman \& Littlefield. </bok>

$<$ bok>DeGrazia, D. 1996. Taking Animals Seriously. New York: Cambridge University Press. $</$ bok $>$

$<$ jrn $>$ DeGrazia, D. 1999. The ethics of animal research: What are the prospects for agreement? Cambridge Quarterly of Healthcare Ethics 8: 23-34.</jrn>

$<$ edb>Derbyshire, S. W. G. 2002. Why animals' rights are wrong. In Animal Experimentation: Good or Bad? ed. T. Gilland, 37-55. London: Hodder \& Stoughton Educational.</edb>

<jrn>Derbyshire, S. W. G. 2006. Time to abandon the three r's: Submitting to "refinement, reduction, and replacement" risks the future of animal research. Scientist 20 (2): 23.</jrn>

$<$ jrn $>$ Douglas, K. 2007. Humans have rights, should human-like animals? New Scientist 30: 4649. </jrn>

$<$ jrn $>$ Elliot, C. 2001. Throwing a bone to the watchdog. Hastings Center Report 31: 9-12.</jrn>

$<$ bok>Feldman, F. 1992. Confrontations with the Reaper: A Philosophical Study of the Nature and Value of Death. New York: Oxford University Press. </bok>

<eref>Feldhahn, S., and D. Glass. 2006. Woman to woman. Topic: Animal rights vs. animal welfare. http://tucsoncitizen.com/morgue/2006/07/05/17937-woman-to-woman-doeshuman-consumption-trump-animal-rights/ (accessed July 11, 2011).</eref>

$<$ jrn $>$ Fink, C. K. 1991. Animal experimentation and the argument from limited resources. Between the Species 7: 90-96.</jrn>

<edb>Frey, R. G. 2000. Justifying animal experimentation: The starting point. In Why Animal Experimentation Matters, ed. E. F. Paul and J. Paul, 197-214. New Brunswick, NJ: Transaction Publishers. $</$ edb $>$

$<$ jrn >Gregory, T. R. 2000. The failure of traditional arguments on the vivisection debate. Public Affairs Quarterly 14: 159-182.</jrn>

<bok>Jamieson, D. 2002. Morality's Progress: Essays on Humans, Other Animals and the Rest of Nature. Oxford: Oxford University Press. $</$ bok $>$

$<$ bok>Lindemann, H. 2006. An Invitation to Feminist Ethics. New York: McGraw Hill.</bok> <bok>Machan, T. R. 2004. Putting Humans First. Lanham, MD: Rowman \& Littlefield.</bok> $<$ jrn>McInerney, J. D., A. R. Morrison, and J. R. Schrock. 2004. Reaction to "How we treat our relatives." American Biology Teacher 66: 253-254.</jrn>

$<$ bok>Pence, G. E. 2000. Re-Creating Medicine: Ethical Issues at the Frontiers of Medicine. Lanham, MD: Rowman \& Littlefield. </bok>

$<$ bok>Rachels, J. 1996. Can Ethics Provide Answers? Lanham, MD: Rowman \& Littlefield.</bok> 
<bok>Regan, T. 2001. Defending Animal Rights. Chicago: University of Illinois Press.</bok>

$<$ bok>Rollin, B. E. 1992. Animal Rights and Human Morality. Rev. ed. New York: Prometheus Books. $</$ bok>

$<$ bok>Rollin, B. E. 2006. Science and Ethics. New York: Cambridge University Press. </bok> $<$ bok>Singer, P. 2002. Animal Liberation. 3rd ed. New York: Ecco. </bok>

<eref>Truth, S. 1851. Ain't I a woman? http://www.fordham.edu/halsall/mod/sojtruthwoman.html (accessed July 11, 2011).</eref>

$<$ bok>U.S. Centers for Disease Control (US CDC). 1997. Atlas of United States Mortality. Washington, DC: CDC. $</$ bok $>$

$<$ bok>U.S. Department of Agriculture (USDA). 2000. Rats/mice/and birds database: Researchers, breeders, transporters, and exhibitors. A database prepared by the Federal Research Division. Washington, DC: Library of Congress, United States Department of Agriculture's Animal Plant Health Inspection Service.</bok>

$<$ jrn $>$ Vance, R. P. 1992. An introduction to the philosophical presuppositions of the animal liberation/rights movement. Journal of the American Medical Association 268: 17151719. </jrn>

<bok>Zamir, T. 2007. Ethics and the Beast: A Speciesist Argument for Animal Liberation. Princeton, NJ: Princeton University Press. $</$ bok $>$ 